\title{
Pharmacological genome demethylation increases radiosensitivity of head and neck squamous carcinoma cells
}

\author{
JUERGEN BRIEGER, SYLVIA A. MANN, WARUT PONGSAPICH, DIMITRIOS KOUTSIMPELAS \\ KAI FRUTH and WOLF J. MANN \\ Molecular Tumorbiology, Department of Otorhinolaryngology, Head and Neck Surgery, University \\ Medical Center of the Johannes Gutenberg University, Mainz, Germany
}

Received September 9, 2011; Accepted October 24, 2011

DOI: $10.3892 /$ ijmm.2011.843

\begin{abstract}
Aberrant inactivation of tumor suppressor genes by promoter hypermethylation has been recognized as a crucial step of tumor development and is related to aggressiveness and therapy resistance. To identify potential novel treatment strategies, we evaluated pharmacological genome demethylation for the increase of irradiation treatment effectiveness in head and neck squamous cell carcinoma (HNSCC) in this in vitro study. HNSCC cells were cultured with 2 different concentrations of 5-azacytidine (5-Aza) for $72 \mathrm{~h}$, followed by a single fraction irradiation with 4 or $50 \mathrm{~Gy}$, respectively. To show successful genome demethylation, the methylation status of the tumor suppressor gene hicl (hypermethylated in cancer) promoter was analyzed by methylation specific PCR (MSP) as well as hic1 transcription by quantitative RT-PCR. Survival, apoptosis, viability, and migration of the tumor cells were analyzed as functional parameters of combined treatment response. After 5-Aza treatment the hic1 promoter was demethylated and gene transcription restored demonstrating genome demethylation. 5-Aza treated cells tended to be less viable and showed decreased survival indicated by lower colony numbers. Apoptosis and migration were not affected. The combined application of irradiation and 5-Aza significantly reduced survival compared to the single treatments. Accordingly, apoptosis was strongly increased after combined 4 Gy/5-Aza treatment. Viability was not additionally affected by combined treatment. Migration was affected weakly by combined high dosage irradiation/5-Aza treatment. Our data show that the combined application of 5-Aza and irradiation is effective in vitro. A demethylating concept prior to irradiation
\end{abstract}

Correspondence to: Dr Jürgen Brieger, Department of Otorhinolaryngology, Head and Neck Surgery, University Medical Center of the Johannes Gutenberg University, Mainz Building 102, 2nd floor, Part D Langenbeckstrasse 1, D-55101 Mainz, Germany

E-mail: juergen.brieger@unimedizin-mainz.de

Key words: head and neck squamous cell carcinoma, epigenetics, promoter hypermethylation, irradiation, resistance, azacytidine, demethylation should be further evaluated for its potential to reduce irradiation resistance.

\section{Introduction}

Squamous cell carcinomas of the head and neck (HNSCC) are the sixth most common malignancy in the USA, and the number of patients newly diagnosed is still increasing (1). Many patients present with locally advanced disease and require a multidisciplinary approach using some combination of surgery, radiotherapy, and chemotherapy (2). However, despite improvements in the treatment of this disease, over the last decades 5-year survival rate has remained largely unchanged. Therefore, the development of treatment strategies overcoming tumor resistance is a permanent urgent aim. The loss of genomic material is related to tumorigenesis and progression. Frequently, tumor suppressor genes (TSG) are deleted (3-6). Inactivated TSGs are recognized to be related to cancer development and more recently as a mechanism of tumor resistance. Beside losses and mutations, epigenetic silencing is another mechanism of TSG inactivation (7), and not surprisingly, the hypermethylation of a multitude of TSG gene promoters could be described for several malignancies (8). Reversal of DNA-repair gene silencing by demethylating treatment with 5-azacytidine (5-Aza) has been shown to reduce therapy resistance in mice (9).5-Aza is a drug successfully used for the normalization of promoter methylation status and gene expression in acute myeloid leukemia and myelodysplastic syndrome $(10,11)$ demonstrating the clinical relevance of gene regulation by promoter hypermethylation. In a recent report we were able to demonstrate the re-expression of hic1 (hypermethylated in cancer) in HNSCC cell lines by the use of 5-Aza (12). Hic1 is a zinc-finger transcription factor and a candidate tumor suppressor gene $(13,14)$ implicated in the tumorigenesis of squamous cell carcinomas (SCC) $(12,15)$. In our published experiments functional consequences of demethylating treatment were decreased proliferative activity as well as reduced colony forming ability of the cells. These data prompted us to speculate that pharmacological unmasking of hypermethylated TSGs may be beneficial in terms of reducing tumor radiation resistance. Here, we report on the functional consequences of a 5-Aza treatment of HNSCC cells in vitro and discuss this treatment as a radiosensitizing strategy. 


\section{Materials and methods}

Cell culture. For our experiments we used the head and neck squamous cell carcinoma cell line HNCCUM-01T (16). This cell line has been used in previous hypermethylation experiments (12). The cell line was maintained in DMEM/Ham's F12 (PAA), supplemented with 5\% FCS (Greiner), and antibiotic solution $(100 \mathrm{U} / \mathrm{ml}$ penicillin and $100 \mu \mathrm{g} / \mathrm{ml}$ streptomycin; PAA) at $37^{\circ} \mathrm{C}$ in $5 \% \mathrm{CO}_{2}$. Cells were treated for $72 \mathrm{~h}$ with 0.2 and $2 \mu \mathrm{M}$ 5-Aza $\left(\right.$ Vidaza $\left.^{\circledR}\right)$ (Sigma-Aldrich).

DNA isolation, bisulfite modification and MSP (methylation specific PCR). To demonstrate successful DNA-demethylation, we performed a methylation-specific PCR analyzing the hicl-promoter as a surrogate marker. The procedure has been detailed before (12). In brief, genomic DNA was extracted and subjected to bisulfite treatment (17). Methylation of the hic1 promoter was assessed by the use of methylated or unmethylated specific primers, respectively. The 95-bp and 118-bp PCR products, respectively, were separated by electrophoresis on a $2 \%$ agarose gel and stained with ethidium bromide. Distilled water was used as negative control. Bisulfite-treated lymphocyte DNA from healthy volunteers served as a positive control for unmethylated DNA. This DNA was methylated by the use of Sss1 methyltransferase (NEB) and used after bisulfite modification as a positive control for amplification of methylated DNA.

RNA extraction and hicl quantitative real-time PCR (qPCR). For evaluation of hicl re-expression after demethylating treatment, we performed a hic1-specific qPCR analysis. The method has been described before by us (12). Briefly, total RNA was isolated from the cells to be analyzed by the use of the NucleoSpin ${ }^{\circledR}$ RNA II-kit (Macherey-Nagel). cDNA was generated using random primers and M-MLV (Promega) and subjected for hicl qPCR (Assay-ID: Hs00948220_m1, Applied Biosystems). As endogenous reference the huPO-gene was used and relative expression levels were calculated by the $2^{-\Delta \Delta C T}$ method (18). The values were related to a calibrator, set as 1 .

Viability. HNCCUM-01T treated with 0.2 or $2 \mu \mathrm{M} 5$-Aza, were dispersed after $72 \mathrm{~h}$ by trypsin digestion and resuspended in standard media. Controls were cultured in parallel. Cells were then irradiated immediately with 4 or $50 \mathrm{~Gy}$, using a gamma source $\left(\mathrm{Cs}^{137}\right)$. Mock-irradiated cells were processed in parallel. After irradiation cells were cultured for additional $24 \mathrm{~h}$ and then viability was measured. In brief, $10 \% \mathrm{v} / \mathrm{v}$ Alamar Blue reagent (Biozol) was added to each well. The Alamar Blue ${ }^{\circledR}$ assay is based on a redox indicator, changing its color from blue (oxidized) to fluorescent red (reduced). After $3 \mathrm{~h}$ relative fluorescence units, indicating cellular metabolism, corresponding to the cellular viability and proliferative activity (19), were determined by the use of a Fluoroscan Ascent-reader (Labsystems). Cell numbers were determined with $1 \mathrm{ml} 0.2 \%$ crystal violet (N-hexamethyl pararosanilin) in PBS for $10 \mathrm{~min}$ (20). For quantification, cells were lysed with acetic acid $(10 \%)$. The colorimetric measurement $(540 \mathrm{~nm})$ of the dye saturation was proportional to the number of cells. By crystal violet staining measured cell numbers were used for normalization of the viability data.
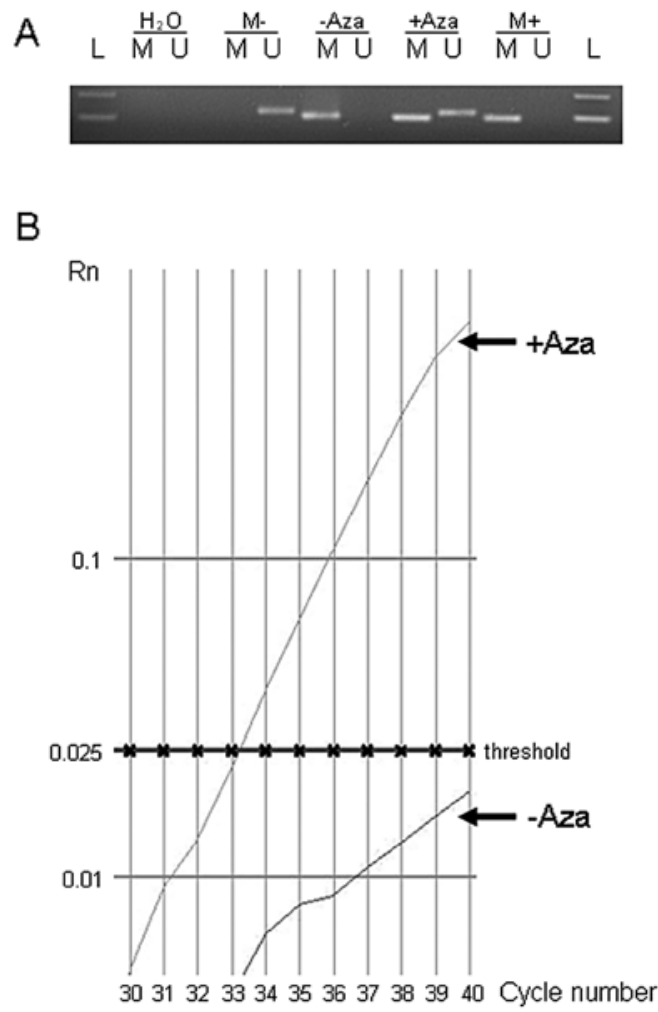

Figure 1. Demethylation by 5-Aza treatment. (A), MSP analysis in 5-Aza treated and untreated HNCCUM-01T cells. Bisulphite-modified DNA was amplified with hic1 primers specific for unmethylated (U) and methylated (M) DNA. 5-Aza treatment with $2 \mu \mathrm{M}(+\mathrm{Aza})$ resulted in demethylation of the DNA indicated by amplification of the hicl promoter by the use of unmethylated-specific primers. Size of PCR products are $118 \mathrm{bp}$ and $95 \mathrm{bp}$ respectively. L, 100-bp ladder. $\mathrm{H}_{2} \mathrm{O}$, negative control, $\mathrm{M}+$, methylated DNA, M-, unmethylated DNA. B, qPCR of hic1. Re-expression of hicl after 5-Aza treatment indicates hic1 promoter unmasking by 5-Aza. The threshold cycle shifted from $\mathrm{Ct}>40$ to $\mathrm{Ct} 33$ after 5 -Aza treatment corresponding to over hundred times the baseline hic1 expression.

Apoptosis. HNCCUM-01T were treated as described for the viability assay. For apoptosis measurement we used the Annexin V FITC apoptosis detection kit (Calbiochem) according to the manufacturer's instructions. The percentages of apoptotic cells were calculated compared to the control. The control was set as $100 \%$.

Colony formation assay. Cells were treated as described for viability measurement, seeded and cultured for 14 days including the appropriate 5-Aza-concentrations. After fixation and staining colonies were counted. The method has been described in detail by us before (12).

Migration. After $72 \mathrm{~h}$ of cell treatment, $3 \times 10^{5}$ cells $/ \mathrm{ml}$ were seeded in the upper chamber of a transwell chamber system (8.0 $\mu \mathrm{m}$ pore polycarbonate membrane, Corning). The membrane served as a barrier to discriminate migrated from non-migrated cells. For quantification, the migrated cells were stained with crystal violet the next day.

Statistics. To analyze treatment responses, obtained data were compared to the controls using ANOVA followed by the Tukey post test. For comparison of single treatments, one-way paired $\mathrm{t}$-tests were used. Shown are the mean \pm SEM. 
A

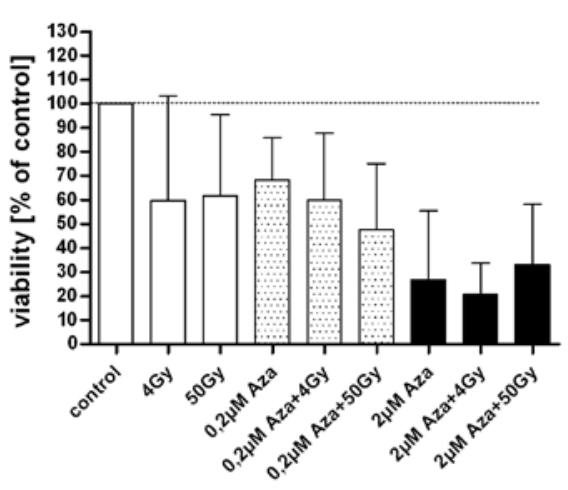

C

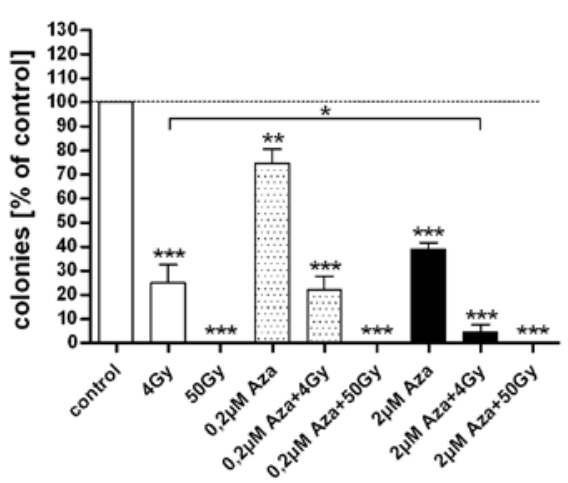

B

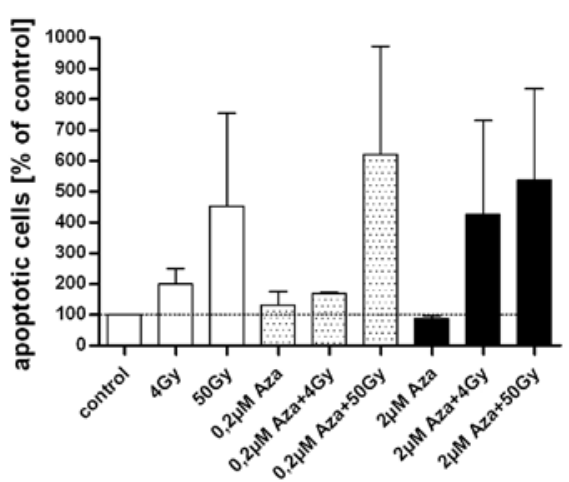

D

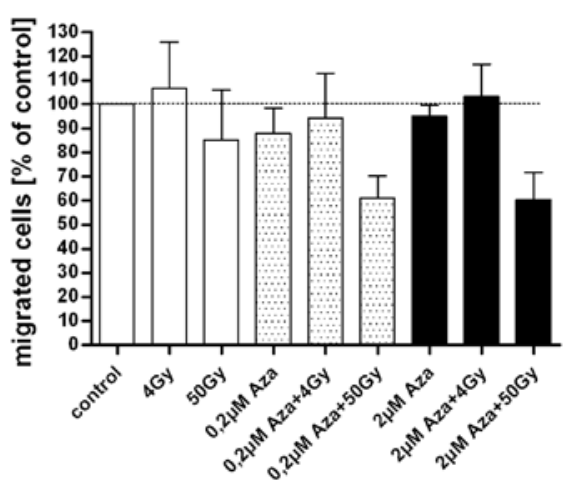

Figure 2. Functional impact of 5-Aza treatment for radiation response. HNCCUM-01T cells were treated for $72 \mathrm{~h}$ with 5-Aza, followed by the functional assays (A) Cell viability measured by the Alamar Blue assay was lowered at both 5-Aza concentrations. (B) Apoptosis was strongly increased by combined application of $2 \mu \mathrm{M} 5$-Aza and $5 \mathrm{~Gy}$. Level of significance was not reached in (A) and (B) due to high variability. (C) Colony assay indicated significantly reduced survival after 5-Aza treatment $(\mathrm{P}<0.01)$, as well as after irradiation $(\mathrm{P}<0.001)$. Combined treatment resulted in additional reduced survival at $4 \mathrm{~Gy}(\mathrm{P}<0.05)$, comparable as it has been observed for apoptosis (B). (D) Migration was only slightly reduced after 50 Gy irradiation single as well as after combined treatment. Controls were set as $100 \%$ (dotted line). Shown are mean values \pm SD of a minimum of 3 independent experiments. The data of controls and Aza-treated cells in (C) and (D) have been shown before (12). ${ }^{*} \mathrm{P}<0.05 ;{ }^{* *} \mathrm{P}<0.01 ;{ }^{* * *} \mathrm{P}<0.001$.

\section{Results}

MSP-analysis and gene activation after 5-Aza treatment. To target the question if a demethylating treatment of HNSCC cells results in the re-expression of formerly inactivated TSGs and if this results in an increased response to irradiation, we treated the HNSCC cell line HNCCUM-01T with 2 dosages of 5-Aza shown before to be effective in demethylating DNA. After 5-Aza treatment we observed that the frequently hypermethylated in HNSCC TSG hicl was demethylated and re-expressed (Fig. 1).

Functional impact of demethylating treatment for radiation response of cancer cells. We evaluated the effectiveness of a combined irradiation/5-Aza treatment concept to increase radiation response of the tumor cells. The Alamar Blue assay revealed that the measured viability of the surviving cells after treatment tended to dose-dependently decrease by 5-Aza, largely irrespective of the irradiation dosage (Fig. 2A). Apoptosis was not induced in any concentration of single treatment with 5-Aza. After 4 Gy irradiation, apoptotic cell counts were doubled compared to the control, but did not further increase after the additional application of $0.2 \mu \mathrm{M}$ 5-Aza. However, the addition of $2 \mu \mathrm{M}$ 5-Aza in combination with 4 Gy irradiation resulted in an apoptotic rate of $427 \%$ of the untreated control, corresponding to a doubling of that of the single irradiation treatment or the low level Aza/4 Gy combination treatment. Irradiation treatment of $50 \mathrm{~Gy}$ resulted in no further increased levels of apoptosis, remaining comparable to the combined $2 \mu \mathrm{M} 5-\mathrm{Aza} / 4$ Gy treatment (Fig. 2B). In the survival assay (Fig. 2C) we observed both a 5-Aza dose dependent as well as a radiation dose-dependent reduction of the colony forming capacity. Corresponding to the apoptosis data we found strongly decreased numbers of colonies $(\mathrm{P}<0.05)$ compared to $0.2 \mu \mathrm{M}$ Aza/4 Gy or $4 \mathrm{~Gy}$ alone after the combined application of $2 \mu \mathrm{M}$ 5-Aza and $4 \mathrm{~Gy}$, thus indicating again a combination effect. The apoptosis and survival data indicate that addition of 5-Aza strongly increases irradiation effectiveness at the clinical relevant dose of $4 \mathrm{~Gy}$. Finally, we analyzed the migratory activity of treated cells and found slightly reduced migration after combined application of 50 Gy and 5-Aza (Fig. 2D), suggesting only a minor effect.

\section{Discussion}

We evaluated in vitro the potential of 5-Aza to increase radiation response of HNSCC cells and found strong evidence that 
5-Aza impairs the cellular resistance mechanism increasing radiation effectiveness.

Tumor suppressor genes are frequently inactivated in cancer thus increasing proliferation, decreasing apoptosis and affecting other tumor resistance mechanisms. Mutations or epigenetic silencing may switch off for cellular homeostasis relevant TSGs (21). Recently, we demonstrated that promoter demethylation by 5-Aza treatment is effective in restoration of hicl expression, a proposed TSG relevant for the development of epithelial cancers in HNSCC with consequences for cellular survival and proliferation (12). Others showed the value of a demethylating treatment of AML and MDS in a clinical setting $(10,11)$ and in cell culture models of pancreatic, prostate, colon, and brain tumors radiosensitizing effects have been reported $(22,23)$. However, the relevance of genome hypermethylation for HNSCC radiation resistance has not been analyzed so far. Therefore, we now analyzed the combined application of irradiation and 5-Aza in a cell culture model utilizing several functional assays. The aim was the collection of data encouraging the further evaluation of a demethylating treatment schedule for the reduction of HNSCC irradiation resistance.

For irradiation experiments we used the therapeutical applicable single dosage of 4 Gy and to stimulate strong effects a maximum of 50 Gy. Our Alamar Blue data showed that viability, roughly reflecting metabolic activity of the cell, is essentially reduced by 5-Aza and to a lesser extent by irradiation. In the colony assay we found both, an irradiation effect and an 5-Aza effect. Moreover, a significant combination effect after the application of 5-Aza with 4 Gy irradiation was observed. A comparable (but due to high standard deviation not statistically significant) result was observed by apoptosis measurement after 5-Aza/4 Gy. One mechanism of irradiation action is the initiation of apoptosis via DNA strand breaks. This pathway is frequently impaired in cancer. Therefore, our finding is in line with the assumption that demethylation overcomes apoptosis blockade and restores susceptibility to apoptosis induction by irradiation.

Collectively, these data suggest that tumor cells die of irradiation and that the surviving cells are metabolically hampered by 5-Aza. The observed combination effect in the colony assay after combined 5-Aza/4 Gy treatment may be explainable by these convergent responses. Migration has been affected only weakly and only after 50 Gy irradiation. This seems conclusive as migration is not related to apoptosis and is not expected to be coupled to metabolism.

We demonstrated before that demethylation is achievable within $72 \mathrm{~h}$ and persists for up to 4 weeks (12). These data suggest that promoter demethylation prior to and its maintenance during the course of irradiation is feasible. The standard daily dosage of radiation treatment to date is 2 Gy. However, enhanced daily dosages with single fractions up to $4 \mathrm{~Gy}$ are under evaluation. Thus, the observed strongly enhanced responses to $4 \mathrm{~Gy}$ irradiation after simultaneous application of 5-Aza might gain increasing clinical relevance.

In summary, our findings show the relevance of hypermethylation for radiation resistance of HNSCC. The data indicate that demethylation and irradiation corrupt cells in a cooperative manner by interfering with convergent mechanisms, resulting in the observed desired combination effects. The further evaluation of demethylating active drugs as a potential radiosensitizing treatment option in HNSCC therapy is strongly warranted.

\section{Acknowledgements}

We are greatly indebted to Ms. Simone Mendler and Ms. Bettina Mros for their excellent technical support. This work was funded by a grant provided by the Foundation Tumour Research Head and Neck, Wiesbaden, Germany. The foundation is a non-profit organization. The funders played no role in the experiment design, execution, analysis or preparation of the paper.

\section{References}

1. Jemal A, Siegel R, Ward E, Hao Y, Xu J, Murray T and Thun MJ: Cancer statistics. CA Cancer J Clin 58: 71-96, 2008.

2. Haddad RI and Shin DM: Recent advances in head and neck cancer. N Engl J Med 359: 1143-1154, 2008.

3. Kim MM and Califano JA: Molecular pathology of head-andneck cancer. Int J Cancer 112: 545-553, 2004.

4. Califano J, van der Riet P, Westra W, Nawroz H, Clayman G, Piantadosi S, Corio R, Lee D, Greenberg B, Koch W and Sidransky D: Genetic progression model for head and neck cancer: implications for field cancerization. Cancer Res 56: 2488-2492, 1996.

5. Gollin SM: Chromosomal alterations in squamous cell carcinomas of the head and neck: window to the biology of disease (Review). Head Neck 23: 238-253, 2001.

6. Brieger J, Jacob R, Riazimand HS, Essig E, Heinrich UR, Bittinger $\mathrm{F}$ and Mann WJ: Chromosomal aberrations in premalignant and malignant squamous epithelium. Cancer Genet Cytogenet 144: 148-155, 2003.

7. Baylin SB, Esteller M, Rountree MR, Bachman KE, Schuebel K and Herman JG: Aberrant patterns of DNA methylation, chromatin formation and gene expression in cancer (Review). Hum Mol Genet 10: 687-692, 2001.

8. Esteller M, Corn PG, Baylin SB and Herman JG: A gene hypermethylation profile of human cancer. Cancer Res 61: 3225-3229, 2001.

9. Plumb JA, Strathdee G, Sludden J, Kaye SB and Brown R: Reversal of drug resistance in human tumor xenografts by 2'-deoxy-5-azacytidine-induced demethylation of the hMLH1 gene promoter. Cancer Res 60: 6039-6044, 2000.

10. Daskalakis M, Nguyen TT, Nguyen C, Guldberg P, Kohler G, Wijermans P, Jones PA and Lubbert M: Demethylation of a hypermethylated P15/INK4B gene in patients with myelodysplastic syndrome by 5 -Aza-2'-deoxycytidine (decitabine) treatment. Blood 100: 2957-2964, 2002.

11. Ruter B, Wijermans PW and Lubbert M: DNA methylation as a therapeutic target in hematologic disorders: recent results in older patients with myelodysplasia and acute myeloid leukaemia. (Review) Int J Hematol 80: 128-135, 2004.

12. Brieger J, Pongsapich W, Mann SA, Hedrich J, Fruth K, Pogozelski B and Mann WJ: Demethylation treatment restores hicl expression and impairs aggressiveness of head and neck squamous cell carcinoma. Oral Oncol 46: 678-683, 2010.

13. Bardwell VJ and Treisman R: The POZ domain: a conserved protein-protein interaction motif. Genes Dev 8: 1664-1677, 1994.

14. Wales MM, Biel MA, el Deiry W, Nelkin BD, IssaJP, Cavenee WK, Kuerbitz SJ and Baylin SB: p53 activates expression of HIC-1, a new candidate tumour suppressor gene on 17p13.3. Nat Med 1: 570-577, 1995.

15. Chen WY, Zeng X, Carter MG, Morrell CN, Chiu Yen RW, Esteller M, Watkins DN, Herman JG, Mankowski JL and Baylin SB: Heterozygous disruption of Hicl predisposes mice to a gender-dependent spectrum of malignant tumors. Nat Genet 33: 197-202, 2003

16. Welkoborsky HJ, Jacob R, Riazimand SH, Bernauer HS and Mann WJ: Molecular biologic characteristics of seven new cell lines of squamous cell carcinomas of the head and neck and comparison to fresh tumor tissue. Oncology 65: 60-71, 2003.

17. Herman JG, Graff JR, Myöhänen S, Nelkin BD and Baylin SB: Methylation-specific PCR: a novel PCR assay for methylation status of CpG islands. Proc Natl Acad Sci USA 93: 9821-9826, 1996. 
18. Livak KJ and Schmittgen TD: Analysis of relative gene expression data using real-time quantitative PCR and the 2(-Delta Delta C(T)) Method. Methods 25: 402-408, 2001.

19. Ahmed SA, Gogal RM Jr and Walsh JE: A new rapid and simple non-radioactive assay to monitor and determine the proliferation of lymphocytes: an alternative to $\left[{ }^{3} \mathrm{H}\right]$ thymidine incorporation assay. J Immunol Methods 170: 211-224, 1994.

20. Gillies RJ, Didier N and Denton M: Determination of cell number in monolayer cultures. Anal Biochem 159: 109-113, 1986.

21. Bennett KL, Karpenko M, Lin MT, Claus R, Arab K, Dyckhoff G, Plinkert P, Herpel E, Smiraglia D and Plass C: Frequently methylated tumor suppressor genes in head and neck squamous cell carcinoma. Cancer Res 68: 4494-4499, 2008.
22. Dote H, Cerna D, Burgan WE, Carter DJ, Cerra MA, Hollingshead MG, Camphausen K and Tofilon PJ: Enhancement of in vitro and in vivo tumor cell radiosensitivity by the DNA methylation inhibitor zebularine. Clin Cancer Res 11: 45714579,2005

23. Hofstetter B, Niemierko A, Forrer C, Benhattar J, Albertini V, Pruschy M, Bosman FT, Catapano CV and Ciernik IF: Impact of genomic methylation on radiation sensitivity of colorectal carcinoma. Int J Radiat Oncol Biol Phys 76: 1512-1519, 2010. 